\title{
Pelabelan 0-Anti Ajaib dan 2-Anti Ajaib untuk Graf Tangga $L_{n}^{m}$
}

\section{0-Antimagic and 2-Antimagic Labeling for Ladder Graph $L_{n}^{m}$}

\author{
Quinoza Guvil $^{1)}$, Roni Tri Putra ${ }^{2)}$ \\ ${ }^{1)}$ Jurusan Teknik Geodesi, Institut Teknologi Padang, Telp. 0751-7055202. \\ Email: quinozaguvil@gmail.com \\ ${ }^{2)}$ Jurusan Teknik Sipil, Politeknik Negeri Padang, Kampus Limau Manis Padang 25163 Telp. 0751- \\ 72590 Fax. 0751-72575. Email : putra_tryronny@yahoo.co.id
}

\begin{abstract}
For a connected graph $G$ and a subset $S$ of $V(G), S \subseteq V(G)$. For a vertex $v \in V(G)$, the distance betwen $v$ and $S$ is $d(v, S)=\min \{d(v, x) \mid x \in S\}$. For an ordered k-partition of $V(G), \Pi=\left\{S_{1}, S_{2}, \ldots, S_{k}\right\}$, the representation of $v$ with respect to $\Pi$ is $r(v \mid \Pi)=\left(d\left(v, S_{1}\right), d\left(v, S_{2}\right), \ldots, d\left(v, S_{k}\right)\right)$. The k-partition $\Pi$ is a resolving partition if $r(v \mid \Pi)$ are distinct for every $v \in V(G)$. The minimum $k$ for which there is a resolving partition of $V(G)$ is the partition dimension of $G, p d(G)$. In this paper will shown resolving partition of connected graph $G$ order $n$ where $n \geq 3$ is a bipartite graph. Then it is shown dimension partition of bipartite graph, are $p d\left(K_{s, t}\right)=n-1$.
\end{abstract}

Key words: Connected Graph, Bipartite Graph, Resolving Partition and Dimension Partition

\section{PENDAHULUAN}

Teori graf merupakan salah satu bidang dalam matematika yang cukup penting untuk dipelajari dan dikembangkan. Salah satu topik kajian dalam teori graf adalah pelabelan graf. Objek kajian pada graf secara umum direpresentasikan oleh titik (vertex), sisi (edge), dan muka (face) yang disebut label. Pelabelan pertama kali diperkenalkan oleh Sedlàček (1964), kemudian Stewart (1966), Kotzig dan Rosa (1970). Teori Graf mempunyai berbagai terapan dalam berbagai bidang ilmu pengetahuan, diantaranya dalam model jaringan transportasi, sistem komunikasi, silsilah keluarga, desain arsitektur.

Harstfield dan Ringel (1990) menyatakan bahwa pelabelan tipe $(1,1,1)$ adalah pemetaan satu-satu dari $V \cup E \cup F$ ke suatu himpunan bilangan bulat $\{1,2,3, \ldots,|V(G)|+|E(G)|+|F(G)|\}$.

Pelabelan titik adalah pelabelan dengan daerah asal himpunan titik, pelabelan sisi adalah pelabelan dengan domain himpunan sisi, dan pelabelan muka adalah pelabelan dengan domain himpunan muka.

Jika pada pelabelan bobot titik, bobot sisi, atau bobot muka berbeda, maka pelabelan ini dikatakan dengan pelabelan anti ajaib. Jika bobot muka membentuk barisan aritmatika dengan beda $d$, maka pelabelan tersebut dinamakan pelabelan $\boldsymbol{d}$ anti ajaib, sedangkan pelabelan ajaib jika memiliki bobot titik, bobot sisi, dan bobot muka yang sama, maka pelabelan disebut pelabelan ajaib.

Sejalan dengan masalah yang akan dibahas, penelitian ini mempunyai tujuan untuk menentukan pelabelan anti ajaib untuk graf tangga $L_{n}^{m}$ dimana $n \geq 2$, dan $m \geq 1$ sehingga memiliki pelabelan tipe $(1,1,1)$ dengan $d \in\{0,2\}$.

\section{METODOLOGI}

Metode penelitian dalam tulisan ini adalah pelabelan $d$-anti ajaib untuk plane graf $L_{n}^{m}$ dimana $\mathrm{n} \geq 2$, dan $1 \leq \mathrm{m} \leq 4$ 
dan $d \in\{0,2\}$ sehingga memiliki pelabelan tipe $(1,1,1)$. Serta untuk memeriksa bahwa nilai-nilai dari $g_{1}$ adalah $1,2, \ldots,\left|V\left(L_{n}^{m}\right)\right|$.

Jika $i \in I_{y} j \in J$ dan $m \leq 2$, maka pelabelan sisi $g_{2}$ menggunakan setiap bilangan bulat $1,2, \ldots,\left|E\left(L_{n}^{m}\right)\right|$ tepat satu.

Jika $i \in I, j \in J$ dan $m \geq 3$, maka pelabelan sisi $g_{2} \quad$ berturut-turut $1,2, \ldots, m,(n-1)+5 n-4, m(n-1)+$ $5 n-3$

dan

$m(n-1)+5 n-1, m(n-1)+$

$5 n, \ldots,\left|E\left(L_{n}^{m}\right)\right|+1$

Nama titik dan sisi dari $L_{n}^{m}, n \geq 2,1 \leq m \leq 4$ oleh pelabelan titik $g_{1}$ pelabelan sisi $g_{2}$. Dengan perhitungan langsung kita memperoleh bahwa:

a. Jika j ganjil, $j \in J-\{m+1\}$ dan $i \in I-\{n\}$ maka bobot dari 3-side face (under pelabelan titik $g_{1}$ dan pelabelan sisi $g_{2} 0$ adalah

$w_{g_{1}}\left(f_{i j}\right)=n(3 m+5-3 j)+2-3 i$,

$w_{g_{1}}\left(h_{i, j}\right)=n(3 m+4-3 j)+1-3 i$,

$w_{g_{2}}\left(f_{i, j}\right)=n(2 m-1)-2 m+(5 n-2) j-1+i$, $w_{g_{2}}\left(h_{i, j}\right)=2 m(n-1)+(5 n-2) j-1+i$.

b. Jika j genap, $j \in J-\{m+1\}$ dan $i \in I-\{n\}$ maka bobot dari 3-side face adalah

$$
\begin{aligned}
& v_{g_{1}}\left(f_{i, j}\right)=n(3 m+5-3 j)+1-3 i_{y}, \\
& v_{g_{1}}\left(h_{i, j}\right)=n(3 m+4-3 j)+2-3 i, \\
& v_{g_{2}}\left(f_{i, j}\right)=n(2 m-1)-2 m+(5 n-2) j+i_{,}, \\
& v_{g_{2}}\left(h_{i, j}\right)=2 m(n-1)+(5 n-2) j-2+i .
\end{aligned}
$$

Jika kita menamakan titik dan sisi dari $L_{n}^{m}$ oleh $g_{1}$, masing-masing, maka untuk $n \geq 2$ dan $m \leq 2$ kita memperoleh suatu pelabelan dengan nilai
$1,2, \ldots,\left|V\left(L_{n}^{m}\right)\right|,\left|V\left(L_{n}^{m}\right)\right|+1,\left|V\left(L_{n}^{m}\right)\right|+$ $2, \ldots,\left|V\left(L_{n}^{m}\right)\right|+\left|E\left(L_{n}^{m}\right)\right|$ dan untuk $n \geq$ 2 dan $3 \leq m \leq 4$

kita mempunyai sebuah hasil pelabelan dengan nilai $1,2, \ldots,\left|V\left(L_{n}^{m}\right)\right|,\left|V\left(L_{n}^{m}\right)\right|+1,\left|V\left(L_{n}^{m}\right)\right|+$ $2, \ldots,\left|V\left(L_{n}^{m}\right)\right|+m(n-1)+5 n-$ $4,\left|V\left(L_{n}^{m}\right)\right|+m(n-1)+5 n-$ 3, $\left|V\left(L_{n}^{m}\right)\right|+m(n-1)+5 n-$ $1,\left|V\left(L_{n}^{m}\right)\right|+m(n-1)+5 n, \ldots,\left|V\left(L_{n}^{m}\right)\right|+$ $\left|E\left(L_{n}^{m}\right)\right|+1$.

Kita dapat melihat bahwa bobot dari semua 3-side faces under hasil pelabelan merupakan sebuah himpunan $W$ dari bilangan bulat yang berurutan

$W=\left\{\begin{array}{c}w_{g_{1}}\left(f_{i, j}\right)+3\left|V\left(L_{n}^{m}\right)\right|+w_{g_{2}}\left(f_{i, j}\right): \\ i \in I-\{n\}, j \in J-\{m+1\} \\ \text { dan } j \text { ganjil }\end{array}\right\}$

Lengkapi pelabelan face $g_{3}$ dari $L_{n}^{m}$ sehingga nilai $\left|V\left(L_{n}^{m}\right)\right|+\left|E\left(L_{n}^{m}\right)\right|+2,\left|V\left(L_{n}^{m}\right)\right|+$ $\left|E\left(L_{n}^{m}\right)\right|+3, \ldots,\left|V\left(L_{n}^{m}\right)\right|+\left|E\left(L_{n}^{m}\right)\right|+$ $\left|F\left(L_{n}^{m}\right)\right|$

akan diberikan untuk 3-side face dan tanpa batas eksternal mendapat nilai $\left|V\left(L_{n}^{m}\right)\right|+\left|E\left(L_{n}^{m}\right)\right|+1(j i k a n \geq 2, m \leq 2)$ atau

$\left|V\left(L_{n}^{m}\right)\right|+m(n-1)+5 n-2(j i k a n \geq$ $2,3 \leq m \leq 4$

Kita mampu menyusun nilai face dari 3-sided faces sehingga pelabelan $g_{1}$, $\left|V\left(L_{n}^{m}\right)\right|+g_{2}$ dan $g_{3}$ dikombinasikan bersama dengan memberi suatu pelabelan dari tipe $(1,1,1)$ dimana

(i) Seluruh 3-sided faces memiliki persamaan bobot $6\left|V\left(L_{n}^{m}\right)\right|+2\left|E\left(L_{n}^{m}\right)\right|+\left|F\left(L_{n}^{m}\right)\right|+n+1$ atau

(ii) Bobot dari 3-sided faces membentuk barisan aritmatika dengan beda $\mathrm{d}=2$ 


\section{HASIL DAN PEMBAHASAN}

Banyaknya titik di graf tangga $L_{n}^{m}$ dengan 3-sisi muka adalah $\left|V\left(L_{n}^{m}\right)\right|=v_{\text {, }}$ dan $\left|E\left(L_{n}^{m}\right)\right|=e$, dengan

$$
\begin{aligned}
& v=n(m+1), \\
& e=m(3 n-2)+n-1 .
\end{aligned}
$$

Misal $f_{i, j}$ adalah muka (face) dari graf tangga $L_{n}^{m}$ dengan $i \in I$ dan $j \in J$, maka banyaknya muka $\left|F\left(L_{n}^{m}\right)\right|=f$, dengan

$$
f=2(n-1) m+1 \text {. }
$$

\section{Definisi 1.}

Misal $I=\{1,2, \ldots, n\} \quad$ dan $I=\{1,2, \ldots, m+1\}$ adalah himpunan indeks dimana $n$ adalah titik dan $m$ adalah bidang. Untuk $n \geq 2, m \geq 1$, graf $L_{n}^{m}$ dikatakan graf tangga dengan 3-sisi muka memiliki himpunan titik dan himpunan sisi sebagai berikut:

$V\left(L_{n}^{m}\right)=\left\{x_{i, j}: i \in I\right.$ dan $\left.j \in J\right\}$

$E\left(L_{n}^{m}\right)=\left\{x_{i, j} x_{i+1, j}: i \in I-\{n\}\right.$ dan $\left.j \in J\right\}$

Gambar 1. berikut mengilustrasikan sebuah graf tangga $L_{n}^{m} 3$-sisi muka dengan $m=2$ dan $n=4$.

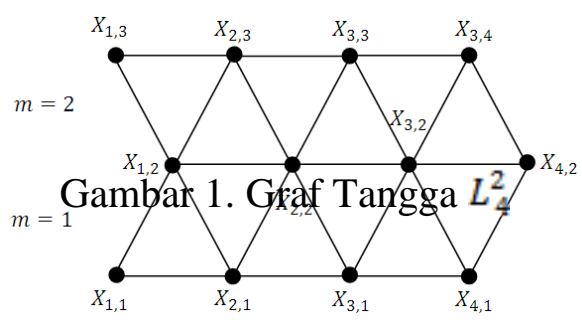

Teorema 1.

Misalkan $\quad L_{n}^{m}, \quad n \geq 2$ dan $m \geq 1$ sebuah graf tangga. Misalkan pelabelan titik $g_{1}$ adalah pelabelan $d_{1}$-anti ajaib, pelabelan sisi $g_{2}$ adalah pelabelan $d_{2}$ anti ajaib merupakan dan $g_{3}$ adalah pelabelan muka untuk $L_{n^{*}}^{m}$ Jika pelabelan $g_{1}$,

$\left|V\left(L_{n}^{m}\right)\right|+g_{2}$ dan $\left|V\left(L_{n}^{m}\right)\right|+\left|E\left(L_{n}^{m}\right)\right|+g_{3}$ digabungkan menjadi sebuah pelabelan $d$ - anti ajaib dari tipe $(1,1,1)$ maka parameter $d \leq 10$.

\section{Bobot Muka $d$-Anti Ajaib pada Graf Tangga $L_{n}^{m}$}

Bobot pada suatu graf $G$ adalah jumlah nilai label untuk setiap titik, sisi, dan muka pada graf $G$ tersebut. Bobot muka dalam pelabelan didefinisikan sebagai jumlah dari hasil pelabelan muka, titik-titik, dan sisi-sisi disekitar muka tersebut.

Pelabelan graf bidang disebut $\boldsymbol{d}$-anti ajaib jika untuk setiap $s$, bobot dari himpunan $s$-sisi muka adalah

$W_{s}=\left\{a_{s}, a_{s}+d, a_{s}+2 d, \ldots, a_{s}+\left(f_{s}-1\right) d\right\}$ untuk suatu $a_{s}$ dan $d$ bilangan bulat $\left(a_{s}>0, d \geq 0\right)$, dimana $f_{s}$ adalah jumlah muka dengan $s$-sisi. Bobot $W_{s}$ berbeda untuk setiap $s$ berbeda.

\section{Teorema 2.}

Jika $n \geq 2, m \geq 1$, dan $d \in\{0,2\}$ maka graf bidang memiliki sebuah pelabelan $d$ anti ajaib dari tipe $(1,1,1)$.

\section{Bukti :}

Lakukan pelabelan untuk semua titik dan pelabelan sisi dengan cara sebagai berikut:

$>$ Pelabelan titik $g_{1}$

$g_{1}\left(x_{i, j}\right)=n(m+2-j)+1-i$, jika $i \in I$ dan $j \in J, I=\{1,2, \ldots, n\}$ dan $J=\{1,2, \ldots, m+1\}$

\section{Pelabelan sisi $g_{2}$}

Berdasarkan Teorema 2, pelabelan sisi $g_{2}$ dapat dikonstruksikan dengan cara sebagai berikut:

$g_{2}\left(x_{i, j} x_{i+1, j}\right)=(n-1) j+1-i$, jika $i \in I-\{n\}$ dan $j \in J$,

Kemudian tentukan bobot dari graf tangga $L_{n}^{m}$ terhadap pelabelan titik $g_{1}$ dan pelabelan sisi $g_{2}$ sebagai berikut:

jika $j$ ganjil, $j \in J-\{m+1\}$ dan $i \in$ $I-\{n\}$ maka

$$
w_{g_{1}}\left(f_{i, j}\right)=g_{1}\left(x_{i, j}\right)+g_{1}\left(x_{i+1, j}\right)+g_{1}\left(x_{i, j+1}\right)
$$




$$
\begin{aligned}
& w_{g_{2}}\left(f_{i, j}\right)=g_{2}\left(x_{i, j} x_{i+1, j}\right)+ \\
& g_{2}\left(x_{i, j} x_{i, j+1}\right)+g_{2}\left(x_{i+1, j} x_{i, j+1}\right)
\end{aligned}
$$

dan

Jika

$j \in J-\{m+1\}$ dan $i \in I-\{n\}$ maka

$v_{g_{1}}\left(f_{i, j}\right)=g_{1}\left(x_{i, j}\right)+g_{1}\left(x_{i+1, j}\right)+g_{1}\left(x_{i+1, j+1}\right)$

$v_{g_{1}}\left(h_{i, j}\right)=g_{1}\left(x_{i, j}\right)+g_{1}\left(x_{i, j+1}\right)+$

$g_{1}\left(x_{i+1, j+1}\right) v_{g_{2}}\left(f_{i, j}\right)=$

$g_{2}\left(x_{i, j} x_{i+1, j}\right)+g_{2}\left(x_{i, j} x_{i+1, j+1}\right)+$

$g_{2}\left(x_{i+1}, x_{i+1, j+1}\right)$

dan

$v_{g_{2}}\left(h_{i, j}\right)=g_{2}\left(x_{i, j} x_{i, j+1}\right)+g_{2}\left(x_{i, j+1} x_{i+1, j+1}\right)+g_{2}\left(x_{i, j} x_{i+1, j+1}\right)$

Setelah bobot titik dan bobot sisi diperoleh, tentukan bobot setiap muka dengan menjumlahkan bobot titik, bobot sisi, dan pelabelan muka $g_{3}$.

jika $j$ ganjil, $j \in J-\{m+1\}$ dan $i \in$

$I-\{n\}$ maka

$$
\begin{aligned}
& W\left(f_{i, j}\right)=w_{g_{1}}\left(f_{i, j}\right)+w_{g_{2}}\left(f_{i, j}\right)+g_{3} \\
& W\left(h_{i, j}\right)=w_{g_{1}}\left(h_{i, j}\right)+w_{g_{2}}\left(h_{i, j}\right)+g_{3}
\end{aligned}
$$

$$
\begin{aligned}
& \text { Jika } \quad j \quad \text { genap, } \\
& j \in J-\{m+1\} \text { dan } i \in I-\{n\} \text { maka } \\
& V\left(f_{i, j}\right)=v_{g_{1}}\left(f_{i, j}\right)+v_{g_{2}}\left(f_{i, j}\right)+g_{3} \\
& V\left(h_{i, j}\right)=v_{g_{1}}\left(h_{i, j}\right)+v_{g_{2}}\left(h_{i, j}\right)+g_{3}
\end{aligned}
$$

Jika bobot titik, bobot sisi, dan pelabelan muka digabungkan, maka diperoleh pelabelan dengan tipe $(1,1,1)$ dimana bobot $W$ membentuk himpunan bilangan bulat berurutan untuk setiap muka yang bertetangga. Bobot muka $W$ dengan 3sisi muka membentuk barisan aritmatika dengan beda $W\left(f_{i, j}\right)-W\left(h_{i, j}\right)=0$ atau $W\left(f_{i, j}\right)-W\left(h_{i, j}\right)=2$.

\section{Contoh 1. (kasus 1: $m=2, n=3$ )}

Misal diberikan $m=2, n=3$. Akan ditunjukkkan bahwa graf tangga $L_{3}^{2}$ memiliki pelabelan muka $d$-anti ajaib dengan 3-sisi muka dimana $d \in\{0,2\}$.
Untuk $m=2, n=3$ diperoleh $I=\{1,2,3\}$ dan $J=\{1,2,3\}$ dan graf tangga $L_{3}^{2}$ memiliki himpunan titik dan himpunan sisi sebagai berikut:

$$
\begin{aligned}
V\left(L_{3}^{2}\right) & =\left\{x_{i, j}: i \in I \text { dan } j \in J\right\} \\
& =\left\{x_{i, 1}, x_{i, 2}, x_{i, 3}\right\} \\
& =\left\{\begin{array}{c}
x_{1,1}, x_{1,2}, x_{1,3}, x_{2,1}, x_{2,2}, x_{2,3} \\
x_{3,1}, x_{3,2}, x_{3,3}
\end{array}\right\} \\
E\left(L_{3}^{2}\right) & =\left\{\begin{array}{c}
x_{i, j} x_{i+1, j}: i \\
\in I-\{n\} \text { dan } j \in J
\end{array}\right\} \\
& \cup\left\{\begin{array}{c}
x_{i, j} x_{i, j+1}: i \in I \text { dan } j \in \\
J-\{m+1\}
\end{array}\right\}
\end{aligned}
$$

$\mathrm{U}$

$\left\{\begin{array}{c}x_{i+1, j} x_{i, j+1}: i \in I-\{n\} \text { dan } \\ j \in J-\{m+1\} \text { dan } j \text { ganjil }\end{array}\right\}$

$\mathrm{u}$

$\left\{\begin{array}{l}x_{i, j} x_{i+1, j+1}: i \in I-\{n\} \text { dan } \\ j \in J-\{m+1\} \text { dan } j \text { genap }\end{array}\right\}$

$$
\begin{aligned}
& =\left\{\begin{array}{c}
x_{1,1} x_{2,1}, x_{1,2} x_{2,2}, x_{1,3} x_{2,3} \\
x_{2,1} x_{3,1}, x_{2,2} x_{3,3}
\end{array}\right\} \\
& \cup\left\{\begin{array}{c}
x_{1,1} x_{1,2}, x_{1,2} x_{1,3}, x_{2,1} x_{2,2} \\
x_{2,2} x_{2,3}, x_{3,1} x_{3,2}, x_{3,2} x_{3,3}
\end{array}\right\} \\
& \cup\left\{x_{2,1} x_{1,2}, x_{3,1} x_{2,2}\right\} \\
& \cup\left\{x_{1,2} x_{2,3}, x_{2,2} x_{3,3}\right\} .
\end{aligned}
$$

Maka diperoleh,

$$
\begin{aligned}
& v=n(m+1)=3(2+1)=9 \\
& e=m(3 n-2)+n-1= \\
& 2(3.3-2)+3-1 \\
& =16 \\
& f=2(n-1) m+1=2(3-1) 2+1=9
\end{aligned}
$$

Selanjutnya dilakukan pelabelan terhadap graf tangga $L_{3}^{2}$ berdasarkan titiktitik, sisi-sisi dan muka internal serta muka eksternal yang telah diperoleh.

Berikut adalah langkah-langkah untuk melabeli graf tangga $L_{3}^{2}$.

1. Akan dilakukan pelabelan titik $g_{1}$ untuk $i \in I$ dan $j \in J$

Berdasarkan definisi dari pelabelan titik $g_{1}$ yaitu, 


$$
g_{1}\left(x_{i, j}\right)=n(m+2-j)+1-i_{y} \text { jika }
$$

$i \in I$ dan $j \in J$

Untuk $i=1$,jika

- $j=1$ maka

$$
g_{1}\left(x_{1,1}\right)=3(2+2-1)+1-1=9
$$$$
j=2 \text { maka }
$$

$$
g_{1}\left(x_{1,2}\right)=3(2+2-2)+1-1=6
$$

- $\quad j=3$ maka

$$
g_{1}\left(x_{1,3}\right)=3(2+2-3)+1-1=3
$$

Untuk $i=2$, jika

- $j=1$ maka

$$
g_{1}\left(x_{2,1}\right)=3(2+2-1)+1-2=8
$$

- $j=2$ maka

$$
g_{1}\left(x_{2,2}\right)=3(2+2-2)+1-2=5
$$

- $j=3$ maka

$$
g_{1}\left(x_{2,3}\right)=3(2+2-3)+1-2=2
$$

$>$ Untuk $i=3$, jika

- $j=1$ maka

$$
g_{1}\left(x_{3,1}\right)=3(2+2-1)+1-3=7
$$

- $j=2$ maka

$$
g_{1}\left(x_{3,2}\right)=3(2+2-2)+1-3=4
$$

- $j=3$ maka

$$
g_{1}\left(x_{3,3}\right)=3(2+2-3)+1-3=1
$$

Pelabelan $g_{1}$ menghasilakan himpunan $\{1,2,3,4,5,6,7,8,9\}$

himpunan label untuk titik.

2. Akan dilakukan pelabelan sisi $g_{2}$ dengan definisi,

* $g_{2}\left(x_{i, j} x_{i+1, j}\right)=(n-1) j+1-i$ jika $i \in I-\{n\}$ dan $j \in J$

> Untuk $i=1$, jika

- $j=1$ maka

$$
g_{2}\left(x_{1,1} x_{2,1}\right)=(3-1) 1+1-1=2
$$

- $j=2$ maka

$$
g_{2}\left(x_{1,2} x_{2,2}\right)=(3-1) 2+1-1=4
$$

- $j=3$ maka

$g_{2}\left(x_{1,3} x_{2,3}\right)=(3-1) 3+1-1=6$

Untuk $i=2$, jika

$j=1$ maka

$g_{2}\left(x_{2,1} x_{3,1}\right)=(3-1) 1+1-2=1$

- $j=2$ maka $g_{2}\left(x_{2,2} x_{3,2}\right)=(3-1) 2+1-2=3$

- $j=3$ maka

$g_{2}\left(x_{2,3} x_{3,3}\right)=(3-1) 3+1-2=5$

* $g_{2}\left(x_{i, j} x_{i, j+1}\right)$

$$
=\left\{\begin{array}{c}
m(n-1)+n(j+1)-2+i, \\
\text { jika } i \in I \text { dan } j \leq 2 \\
m(n-1)+n(j+3)-3+i, \\
\text { jika } i \in I, \text { dan } j \geq 3
\end{array}\right.
$$

Untuk $i=1$, jika

- $j=1$ maka

$g_{2}\left(x_{1,1} x_{1,2}\right)=2(3-1)+3(1+1)-$ $2+1=9$

- $j=2$ maka

$g_{2}\left(x_{1,2} x_{1,3}\right)=2(3-1)+3(2+1)-$ $2+1$

$=12$

Untuk $i=2$, jika

- $j=1$ maka

$g_{2}\left(x_{2,1} x_{2,2}\right)=2(3-1)+3(1+1)-$ $2+2$

$=10$

- $j=2$ maka $g_{2}\left(x_{2,2} x_{2,3}\right)=2(3-1)+3(2+1)-$ $2+2=13$

Untuk $i=3$, jika

$j=1$ maka

$g_{2}\left(x_{3,1} x_{3,2}\right)=2(3-1)+3(1+1)-2+$ $3=11$ 
- $j=2$ maka

$g_{2}\left(x_{3,2} x_{3,3}\right)=2(3-1)+3(2+1)-2+$ $3=14$

$$
g_{2}\left(x_{i+1, j} x_{i, j+1}\right)=(n-1)(m+1)+
$$

$\frac{j-1}{2}(4 n-1)+i$

, jika $i \in I-\{n\}$ dan $j \in J-\{m+1\}$ dan $j$ ganjil,

$>$ Untuk $i=1$, jika

- $j=1$ maka

$g_{2}\left(x_{2,1} x_{1,2}\right)=(3-1)(2+1)+$ $\frac{1-1}{2}(4(3)-1)+1=7$

Untuk $i=2$, jika

- $j=1$

maka

$$
\begin{aligned}
& g_{2}\left(x_{3,1} x_{2,2}\right)=(3-1)(2+1)+ \\
& \frac{1-1}{2}(4(3)-1)+2=8
\end{aligned}
$$

$$
g_{2}\left(x_{i, j} x_{i+1, j+1}\right)=m(n-1)+
$$

$\frac{j}{2}(4 n-1)-1+i$,

jika

$i \in I-\{n\}$ dan $j \in J-\{m+$

1) dan $j$ genap

Untuk $i=1$, jika

- $j=2$ maka

$$
\begin{aligned}
g_{2}\left(x_{1,2} x_{2,3}\right)= & 2(3-1)+\frac{2}{2}(4(3)-1) \\
& -1+1 \\
= & 15
\end{aligned}
$$

Untuk $i=2$, jika

- $j=2$ maka

$$
\begin{aligned}
g_{2}\left(x_{2,2} x_{3,3}\right)= & 2(3-1)+\frac{2}{2}(4(3)-1) \\
& -1+2 \\
= & 16
\end{aligned}
$$

Diperoleh himpunan label untuk sisi berdasarkan pelabelan $g_{2}$ yaitu

$$
\begin{aligned}
g_{2}= & \left\{\left|V\left(L_{3}^{2}\right)\right|+g_{2}\right\} \\
=\{9 & +1,9+2,9+3,9+4,9+5,9 \\
& +6,9+7,9+8,9+9,9+10,9 \\
& +11,9+12,9+13,9+14,9 \\
& +15,9+16\} \\
= & \left\{\begin{array}{c}
10,11,12,13,14,15,16, \\
17,18,19,20,21,22,23,24,25
\end{array}\right\} .
\end{aligned}
$$

3. Akan dilakukan pelabelan muka $g_{3}$ dengan definisi sebagai berikut,

* Himpunan pelabelan muka internal $f_{\text {int }}=\left\{\left|V\left(L_{n}^{m}\right)\right|+\left|E\left(L_{n}^{m}\right)\right|+2,\left|V\left(L_{n}^{m}\right)\right|\right.$ $+\left|E\left(L_{n}^{m}\right)\right|+3,\left|V\left(L_{n}^{m}\right)\right|+\left|E\left(L_{n}^{m}\right)\right|$

$$
+4,\left|V\left(L_{n}^{m}\right)\right|+\left|E\left(L_{n}^{m}\right)\right|+5,
$$

$$
\begin{aligned}
& \left|V\left(L_{n}^{m}\right)\right|+\left|E\left(L_{n}^{m}\right)\right|+6, \\
& \left|V\left(L_{n}^{m}\right)\right|+\left|E\left(L_{n}^{m}\right)\right|+7, \\
& \left.\left|V\left(L_{n}^{m}\right)\right|+\left|E\left(L_{n}^{m}\right)\right|+9\right\}
\end{aligned}
$$

$$
\begin{aligned}
f_{\text {int }}= & \{(9+16+2),(9+16+3), \\
& (9+16+4),(9+16+5), \\
& (9+16+6),(9+16+7), \\
& (9+16+8),(9+16+9)\}
\end{aligned}
$$

$f_{\text {int }}=\{27,28,29,30,31,32,33,34\}$

* Untuk pelabelan muka eksternal

$f_{\text {ext }}=\left|V\left(L_{3}^{2}\right)\right|+\left|E\left(L_{3}^{2}\right)\right|+1$

$$
\begin{aligned}
& =9+16+1 \\
& =26
\end{aligned}
$$

4. Akan ditentukan bobot untuk setiap muka terhadap terhadap pelabelan titik $g_{1}$ dengan cara sebagai berikut,

Jika j ganjil, $j \in J-\{m+1\}$ dan $i \in I-\{n\}$ maka bobot dari 3-sisi muka adalah

$w_{g_{1}}\left(f_{i, j}\right)=n(3 m+5-3 j)+2-3 i$

$$
w_{g_{1}}\left(h_{i, j}\right)=n(3 m+4-3 j)+1-3 i
$$

- Untuk $j=1$ dan $i=1$

$$
\begin{aligned}
w_{g_{1}}\left(f_{1,1}\right)= & 3(3(2)+5-3(1))+2 \\
& -3(1) \\
= & 23
\end{aligned}
$$




$$
\begin{aligned}
w_{g_{1}}\left(h_{1_{1} 1}\right) & =3(3(2)+4-3(1))+1-3(1) \\
& =19
\end{aligned}
$$

- Untuk $j=1$ dan $i=2$

$$
\begin{aligned}
w_{g_{1}}\left(f_{2,1}\right) & =3(3(2)+5-3(1))+2-3(2) \\
& =20
\end{aligned}
$$$$
w_{g_{1}}\left(h_{2,1}\right)=3(3(2)+4-3(1))+1-3(2)
$$$$
=16
$$

Jika j genap, $j \in J-\{m+1\}$ dan $i \in I-\{n\}$ maka bobot dari 3 -sisi muka adalah

$$
\begin{aligned}
& v_{g_{1}}\left(f_{i, j}\right)=n(3 m+5-3 j)+1-3 i \\
& v_{g_{1}}\left(h_{i, j}\right)=n(3 m+4-3 j)+2-3 i
\end{aligned}
$$

- Untuk $j=2$ dan $i=1$

$$
\begin{aligned}
v_{g_{1}}\left(f_{1,2}\right) & =3(3(2)+5-3(2))+1-3(1) \\
& =13 \\
v_{g_{1}}\left(h_{1,2}\right) & =3(3(2)+4-3(2))+2-3(1) \\
& =11
\end{aligned}
$$

- Untuk $j=2$ dan $i=2$

$$
\begin{aligned}
v_{g_{1}}\left(f_{2,2}\right) & =3(3(2)+5-3(2))+1-3(2) \\
& =10 \\
v_{g_{1}}\left(h_{2,2}\right) & =3(3(2)+4-3(2))+2-3(2) \\
& =8
\end{aligned}
$$

Himpunan bobot titik graf

$$
L_{3}^{2}=\{8,10,11,13,16,19,20,23\} \text {. }
$$

5. Akan ditentukan bobot untuk setiap muka terhadap terhadap pelabelan sisi $g_{2}$ dengan cara sebagai berikut,

Jika j ganjil, $j \in J-\{m+1\}$ dan $i \in I-\{n\}$ maka bobot dari 3-sisi muka adalah

$$
\begin{aligned}
w_{g_{2}}\left(f_{i, j}\right)= & g_{2}\left(x_{i, j} x_{i+1, j}\right)+ \\
& g_{2}\left(x_{i, j} x_{i, j+1}\right)+ \\
& g_{2}\left(x_{i+1, j} x_{i, j+1}\right)
\end{aligned}
$$

$$
\begin{aligned}
w_{g_{2}}\left(h_{1,1}\right)= & g_{2}\left(x_{i+1, j} x_{i, j+1}\right)+ \\
& g_{2}\left(x_{i, j+1} x_{i+1, j+1}\right)+ \\
& g_{2}\left(x_{i+1, j} x_{i+1, j+1}\right)
\end{aligned}
$$

- Untuk $j=1$ dan $i=1$

$$
\begin{aligned}
w_{g_{2}}\left(f_{1,1}\right)= & g_{2}\left(x_{1,1} x_{2,1}\right)+g_{2}\left(x_{1,1} x_{1,2}\right) \\
& +g_{2}\left(x_{2,1} x_{1,2}\right) \\
= & 11+18+1 \\
= & 45 \\
w_{g_{2}}\left(h_{1,1}\right)= & g_{2}\left(x_{2,1} x_{1,2}\right)+g_{2}\left(x_{1,2} x_{2,2}\right) \\
& +g_{2}\left(x_{2,1} x_{2,2}\right) \\
= & 16+13+19 \\
= & 48
\end{aligned}
$$

- Untuk $j=1$ dan $i=2$

$$
\begin{aligned}
w_{g_{2}}\left(f_{2,1}\right)= & g_{2}\left(x_{2,1} x_{3,1}\right)+g_{2}\left(x_{2,1} x_{2,2}\right) \\
& +g_{2}\left(x_{3,1} x_{2,2}\right) \\
= & 10+19+17 \\
= & 46
\end{aligned}
$$

$$
\begin{aligned}
w_{g_{2}}\left(h_{2,1}\right)= & g_{2}\left(x_{3,1} x_{2,2}\right)+g_{2}\left(x_{2,2} x_{3,2}\right) \\
& +g_{2}\left(x_{3,1} x_{3,2}\right) \\
= & 17+12+20 \\
= & 49
\end{aligned}
$$

Jika j genap, $j \in J-\{m+1\}$ dan $i \in I-\{n\}$ maka bobot dari 3 -sisi muka adalah

$$
\begin{aligned}
v_{g_{2}}\left(f_{i, j}\right)= & g_{2}\left(x_{i, j} x_{i+1, j}\right)+ \\
& g_{2}\left(x_{i, j} x_{i+1, j+1}\right)+ \\
& g_{2}\left(x_{i+1, j} x_{i+1, j+1}\right) \\
v_{g_{2}}\left(h_{i, j}\right)= & g_{2}\left(x_{i, j} x_{i, j+1}\right)+ \\
& g_{2}\left(x_{i, j+1} x_{i+1, j+1}\right)+ \\
& g_{2}\left(x_{i, j} x_{i+1, j+1}\right)
\end{aligned}
$$

- Untuk $j=2$ dan $i=1$

$$
\begin{aligned}
v_{g_{2}}\left(f_{1,2}\right)= & g_{2}\left(x_{1,2} x_{2,2}\right)+ \\
& g_{2}\left(x_{1,2} x_{2,3}\right)+ \\
& g_{2}\left(x_{2,2} x_{2,3}\right) \\
= & 13+24+22 \\
= & 59
\end{aligned}
$$




$$
\begin{aligned}
v_{g_{2}}\left(h_{1,2}\right)= & g_{2}\left(x_{1,2} x_{1,3}\right)+ \\
& g_{2}\left(x_{1,3} x_{2,3}\right)+ \\
& g_{2}\left(x_{1,2} x_{2,3}\right) \\
= & 21+15+24 \\
= & 60
\end{aligned}
$$

- Untuk $j=2$ dan $i=2$

$$
\begin{gathered}
v_{g_{2}}\left(f_{2,2}\right)=g_{2}\left(x_{2,2} x_{3,2}\right)+g_{2}\left(x_{2,2} x_{3,3}\right)+g_{2}\left(x_{3,2} x_{3,3}\right) \\
=12+25+23 \\
=60 \\
\begin{aligned}
v_{g_{2}}\left(h_{2,2}\right)= & g_{2}\left(x_{2,2} x_{2,3}\right)+g_{2}\left(x_{2,3} x_{3,3}\right)+g_{2}\left(x_{2,2} x_{3,3}\right) \\
& =22+14+25 \\
& =61
\end{aligned}
\end{gathered}
$$

Himpunan bobot sisi graf $L_{3}^{2}=\{45,46,48,49,59,60,60,61\}$.

6. Akan ditentukan bobot muka dari penggabungan bobot titik, bobot sisi dan pelabelan $g_{3}$ dengan cara sebagai berikut:

$$
\begin{aligned}
W_{f_{1,1}} & =w_{g_{1}}\left(f_{1,1}\right)+w_{g_{2}}\left(f_{1,1}\right)+g_{3} \\
& =23+45+31 \\
& =99
\end{aligned}
$$

$$
\begin{aligned}
W_{h_{1,1}} & =w_{g_{1}}\left(h_{1,1}\right)+w_{g_{2}}\left(h_{1,1}\right)+g_{3} \\
& =19+48+32 \\
& =99
\end{aligned}
$$

$$
\begin{aligned}
W_{f_{2,1}} & =w_{g_{1}}\left(f_{2,1}\right)+w_{g_{2}}\left(f_{2,1}\right)+g_{3} \\
& =20+46+33 \\
& =99
\end{aligned}
$$

$$
\begin{aligned}
W_{h_{2,1}} & =w_{g_{1}}\left(h_{2,1}\right)+w_{g_{2}}\left(h_{2,1}\right)+g_{3} \\
& =16+49+34 \\
& =99 \\
W_{f_{1,2}} & =w_{g_{1}}\left(f_{1,2}\right)+w_{g_{2}}\left(f_{1,2}\right)+g_{3} \\
& =13+59+27 \\
& =99
\end{aligned}
$$

$$
\begin{aligned}
W_{h_{1,2}} & =w_{g_{1}}\left(h_{1,2}\right)+w_{g_{2}}\left(h_{1,2}\right)+g_{3} \\
& =11+60+28 \\
& =99 \\
W_{f_{2,2}} & =w_{g_{1}}\left(f_{2,2}\right)+w_{g_{2}}\left(f_{2,2}\right)+g_{3} \\
& =10+60+29 \\
& =99 \\
W_{h_{2,2}} & =w_{g_{1}}\left(h_{2,2}\right)+w_{g_{2}}\left(h_{2,2}\right)+g_{3} \\
& =8+61+30 \\
& =99
\end{aligned}
$$

Jadi diperoleh himpunan bobot muka graf $L_{3}^{2}=\{99,99,99,99,99,99,99,99\}$.

Defenisikan pelabelan titik-titik, sisi-sisi, dan muka berturut-turut sebagai $g_{1}, g_{2}$, dan $g_{3}$. Akan diperoleh pelabelan dengan tipe $(1,1,1)$ dan 3-sisi muka pada graf tangga $L_{3}^{2}$

$$
\begin{aligned}
w_{f_{1,1}} & =w_{g_{1}}\left(f_{1,1}\right)+w_{g_{2}}\left(f_{1,1}\right)+g_{3} \\
& =23+45+3 \\
& =98 \\
W_{h_{1,1}} & =w_{g_{1}}\left(h_{1,1}\right)+w_{g_{2}}\left(h_{1,1}\right)+g_{3} \\
& =19+48+29 \\
& =96 \\
W_{f_{2,1}} & =w_{g_{1}}\left(f_{2,1}\right)+w_{g_{2}}\left(f_{2,1}\right)+g_{3} \\
& =20+46+28 \\
& =94 \\
W_{h_{n_{1}, 1}} & =w_{g_{1}}\left(h_{2,1}\right)+w_{g_{2}}\left(h_{2,1}\right)+g_{3} \\
& =16+49+27 \\
& =92 \\
W_{f_{1,2}} & =w_{g_{1}}\left(f_{1,2}\right)+w_{g_{2}}\left(f_{1,2}\right)+g_{3} \\
& =13+59+34 \\
& =106
\end{aligned}
$$




$$
\begin{aligned}
W_{h_{1,2}} & =w_{g_{1}}\left(h_{1,2}\right)+w_{g_{2}}\left(h_{1,2}\right)+g_{3} \\
& =11+60+33 \\
& =104 \\
W_{f_{2,2}} & =w_{g_{1}}\left(f_{2,2}\right)+w_{g_{2}}\left(f_{2,2}\right)+g_{3} \\
& =10+60+32 \\
& =102 \\
W_{h_{2,2}} & =w_{g_{1}}\left(h_{2,2}\right)+w_{g_{2}}\left(h_{2,2}\right)+g_{3} \\
& =8+61+31 \\
& =100
\end{aligned}
$$

Jadi diperoleh himpunan bobot muka $W=\{92,94,96,98,100,102,104,106\}$.

Dari himpunan bobot muka $W$ pada graf tangga $L_{3}^{2}$ dengan 3-sisi muka membentuk barisan aritmatika dengan beda $d=2$ seperti Gambar 2.

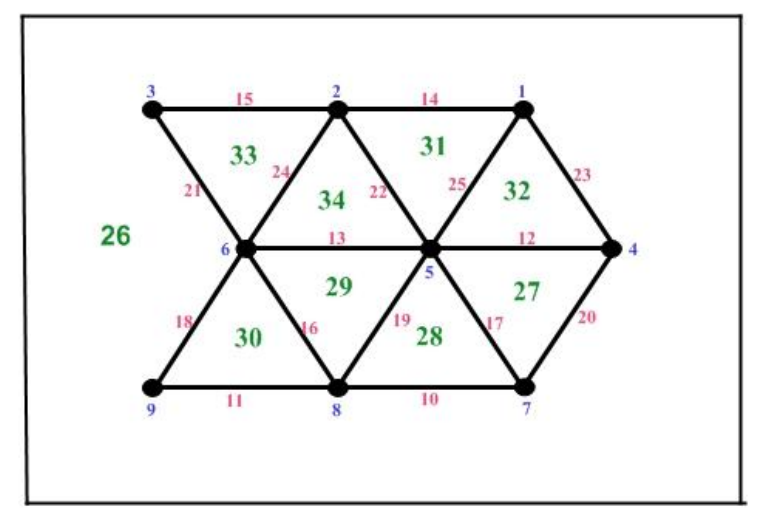

Gambar 2. Pelabelan Tipe $(1,1,1)$

Graf Tangga $L_{3}^{2}$ dengan $d=2$

Setiap 3-sisi muka memiliki bobot muka yang membentuk barisan aritmatika dengan $d \in\{0,2\}$. Dengan demikian pelabelan graf tangga $L_{n}^{m}$ merupakan pelabelan muka $d$-anti ajaib dengan tipe $(1,1,1)$.

\section{SIMPULAN}

Adapun kesimpulan dari penelitian ini bahwa bobot muka dari graf tangga $L_{n}^{m}$ dengan 3 -sisi muka, $n \geq 1$ dan $m \geq 1$ dapat disusun sedemikian sehingga jika pelabelan $g_{1}, \quad\left|V\left(L_{n}^{m}\right)\right|+g_{2} \quad$ dan $g_{3}$ digabung diperoleh pelabelan tipe $(1,1,1)$ dimana

1. Seluruh 3-sisi muka memiliki bobot yang sama untuk $d=0$ dan

2. Bobot dari 3-sisi muka membentuk barisan aritmatika dengan beda $d=2$.

\section{SARAN}

Karena berbagai keterbatasan, penulis menyadari penelitian dan tulisan ini masih banyak kekurangannya. Banyak hal yang belum tercakup dalam penelitan ini. Dalam penelitian ini hanya dibahas pelabelan muka $d$-anti ajaib untuk graf tangga $L_{n}^{m}$ dengan 3-sisi muka. Perlu dikaji lebih lanjut pelabelan muka untuk graf tangga lainnya seperti graf honeycomb dan graf grid.

\section{DAFTAR PUSTAKA}

Baca, M dan Miller,M, 2008, Super EdgeAntimagic Graphs, Brown Walker Press,Boca Raton-Florida.

Bondy, J.A. dan Murty, U.S.R.. 1976. Graph Theory with Applications. The Macmillan Press LTD. London.

Hartsfield, N dan Ringel, G. 1990. Pearls in Graph Theory, Academic Press. Boston.

Ko- Wei Lih. 1983. On Magic and Consecutive Labeling Of Plane Graphs, Utilitas Math. 24 .165-197.

Oss, S.L., Differential Equations, $3^{\text {rd }}$ edition, John Wiley \& Sons, University of New Hampshire, 1984.

Verhultz, Ferdinand, 1990, Nonlinear Differential Equations and Dynamical Systems, Springer Verlag, Berlin.

Wiggins S, 1990, Introduction to Applied Nonlinear Dynamical Systems and 
Chaos, Springer - Verlag, New York.

Wallis, W.D. 2001. Magic Graphs, Birkhauser, Berlin. Boston-Basel.

West, D.B. 1996. An Introduction to Graph

Theory. Prentice - Hall. 